\title{
No Associations Between Single Nucleotide Polymorphisms in Corticoid Receptor Genes and Heart Rate and Cortisol Responses to a Standardized Social Stress Test in Adolescents: The TRAILS Study
}

\author{
Esther M. C. Bouma $\cdot$ Harriëtte Riese $\cdot$ \\ Ilja M. Nolte • Elvira Oosterom • Frank C. Verhulst • \\ Johan Ormel $\cdot$ Albertine J. Oldehinkel
}

Received: 28 January 2010/Accepted: 17 July 2010/Published online: 1 August 2010

(C) The Author(s) 2010. This article is published with open access at Springerlink.com

\begin{abstract}
Previously, sequence variation in the glucocorticoid (GR) and mineralocorticoid (MR) receptor genes (NR3C1 and $\mathrm{NR} 3 \mathrm{C} 2$, respectively) have been found to be associated with physiological stress responses to social stress tests in small samples of adult men and oral contraceptives (OC) using women. Associations between single nucleotide polymorphisms (SNPs) in the GR (23EK-rs6190, 9betars6198, BclI-rs4142324) and the MR gene (I180V-rs5522 and $-2 \mathrm{G} / \mathrm{C}$ (rs2070951) with cortisol and heart rate responses to a performance-related social stress task (public speaking and mental arithmetic) were examined in a large sample $(n=553)$ of adolescents (15-17 years). To make comparisons with previous findings, associations were tested in boys
\end{abstract}

Edited by Tatiana Foroud.

Elvira Oosterom deceased.

E. M. C. Bouma $(\varangle) \cdot$ H. Riese $\cdot$ J. Ormel $\cdot$ A. J. Oldehinkel Department of Psychiatry, Interdisciplinary Center

for Psychiatric Epidemiology and Groningen Graduate School

Medical Sciences, University Medical Center Groningen,

CC72, University of Groningen, P.O. Box 30.001,

9700 RB Groningen, The Netherlands

e-mail: e.m.c.bouma@med.umcg.nl

H. Riese - I. M. Nolte

Department of Epidemiology, Unit of Genetic Epidemiology and Bioinformatics, University Medical Center Groningen,

University of Groningen, Groningen, The Netherlands

E. Oosterom

Department of Genetics, Genome Analysis Facility, University

Medical Center Groningen, University of Groningen, Groningen,

The Netherlands

F. C. Verhulst

Department of Child and Adolescent Psychiatry,

Erasmus Medical Center, Rotterdam, The Netherlands
( $n=277)$, free-cycling (FC) girls $(n=183)$ and OC users $(n=93)$. None of the previously reported associations in adults could be replicated in this large adolescent sample. Explanations for non-replication are discussed.

Keywords Glucocorticoid receptor gene · Mineralocorticoid receptor gene · Non-replication . Multiple testing $\cdot$ False discovery rate

\section{Introduction}

The neuro-endocrine response to stress includes the activation of the sympathetic nervous system, resulting in increased heart rate, and release of cortisol from the adrenal glands. High levels of cortisol lead to negative feedback of the stress response in the brain, by binding to the low affinity glucocorticoid receptor (GR) (de Kloet et al. 2009). The mineralocorticoid receptor (MR) has a high affinity for cortisol and plays a role in the tonic inhibition of the hypothalamic-pituitary-adrenal (HPA) axis (de Kloet et al. 2009).

Responses to stress are influenced by genetic factors (reviewed by DeRijk 2009); the availability and efficiency of corticoid receptors is influenced by variation in the genes coding for them. Small variants, called single nucleotide polymorphisms (SNPs) are commonly present in the GR gene (nuclear receptor subfamily 3, group C, member 1 [NR3C1], OMIM +138040) and the MR gene (nuclear receptor subfamily 3, group C, member 2 [NR3C2], OMIM *600983). SNPs in both genes have been associated with cortisol and heart rate responses to stress (DeRijk 2009) and may convey a risk for stress-related disorders such as depression. This is supported by associations between GR SNPs and major depression (van Rossum et al. 2006; van West et al. 2006) and with depressive symptoms (Kuningas et al. 2006). 
From animal studies we know that synthetic and natural sex hormones influence the response to stress by interacting with both GRs and MRs in the hypothalamus and amygdala (Turner 1997; Chrousos et al. 1998; Levine 2002). These interactions might be different according to genetically based functional differences in cortisol receptors. The results of these type of association studies add to the knowledge if and how genetically based variances in corticoid receptors influence HPA axis and cardiac autonomic responses to social stress. Moreover, gender-specific effects of genes have been associated with vulnerability to stress and depression (Silberg et al. 1999; Kendler et al. 2006), and the underlying mechanisms might involve interactions of female sex hormones with corticoid receptors.

The ER22/23EK (rs6189/rs6190) SNPs (G to A) in exon 2 of the GR gene (Russcher et al. 2005) was associated with corticoid resistance in a pharmacological challenge (Van Rossum et al. 2004), resulting in higher post-dexamethasone cortisol levels. In men, the $\mathrm{G}$ allele of the $\mathrm{BclI}$ SNP in the GR gene was associated with blunted salivary cortisol responses compared to men homozygous for the $\mathrm{C}$ allele (Wüst et al. 2004; Kumsta et al. 2007; Ising et al. 2008). Inverse relations were detected in women [all oral contraceptives (OC) users]; women homozygous for the $\mathrm{G}$ allele displayed higher cortisol responses than $\mathrm{C}$-carriers (Kumsta et al. 2007). Contrary to Kumsta and colleagues, no gender difference was found by Ising et al. (2008); BclI $\mathrm{G}$ allele carriers of both genders displayed lower responses. The 9beta polymorphism in the GR gene is a A-to-G SNP present in the $3^{\prime}$ untranslated region of exon $9 ß$. Both men and women who carried the $G$ allele displayed increased cortisol responses (Kumsta et al. 2007). The MRI180V (rs5522) polymorphism consists of a SNP in exon 2, resulting in an amino acid change in the N-terminal domain of the protein. In vitro, this SNP decreased the transactivation capacity of the protein (DeRijk et al. 2006). Additionally, male carriers of the $\mathrm{C}$ allele displayed enhanced cortisol and heart rate responses to a social stress test (DeRijk et al. 2006). Another G/C SNP, situated two nucleotides before the translation start site of the MR gene (-2G/C, rs2070951rs) was examined in vitro. The $\mathrm{C}$ allele was found to be associated with increased activity of the MR receptor (van Leeuwen et al. 2007). This SNP has not been examined in the context of social stress but was associated with the cortisol awakening response (CAR) after the dexamethasone suppression test in a genderspecific way (Van Leeuwen et al. 2010).

All previous associations were tested in adult samples and included mostly men. If women were included in the samples, they all used OC which are known to influence cortisol measurements (Kirschbaum et al. 1999; Rohleder et al. 2003, but not Brody 2002), which may have implications for the interpretation of previous reported associations in women. The underlying mechanism most likely involves the higher production of cortisol binding globuline (GBC) when estrogen levels are high (Wiegratz et al. 2003). CBG binds free cortisol resulting in less cortisol available to be detected in saliva. Indeed differences have been found according to gender and OC use in adolescence (Bouma et al. 2009). Although studies in adult women reported lower cortisol levels in the follicular phase (when estrogen levels are high) than in the luteal phase (Altemus et al. 1997; Kirschbaum et al. 1999; Wolf et al. 2001; Rohleder et al. 2003), this was not found in adolescent girls (Bouma et al. 2009).

In the present study we investigate if the aforementioned findings in adults could be replicated in adolescent boys and girls. We are the first to include girls using $\mathrm{OC}$ as well as free-cycling (FC) girls in the same study. The influence of the $-2 \mathrm{G} / \mathrm{C}$ SNP in the MR gene is tested for the first time in the context of a social stress situation. In order to compare our results with those of previous findings we analyzed the associations of the SNPs with the physiological responses for boys, FC girls and OC users separately. Since several associations will be tested a correction for the level of significance has to be applied (Sainani 2009).

\section{Materials and methods}

\section{Sample description}

Data were collected in a subsample of the TRacking Adolescents' Individual Lives Survey (TRAILS). TRAILS is prospective cohort study of Dutch (pre)adolescents, with the aim to chart and explain the development of mental health from preadolescence into adulthood, both at the level of psychopathology and the levels of underlying vulnerability and environmental risk. The first wave (T1) ran from March 2001 to July 2002, the second wave (T2) from September 2003 to December 2004, and the third wave (T3) from September 2005 to December 2007. At T1, 2,230 children were enrolled in the study (mean age 11.09, $\mathrm{SD}=0.59)$, response rate $76 \%$, de Winter et al. 2005). At $\mathrm{T} 2,96.4 \%$ of the baseline sample participated again (mean age $13.55, \mathrm{SD}=0.54)$, and at $\mathrm{T} 3$ the response rate was $81.4 \%$ (mean age $16.13, \mathrm{SD}=0.59$ ). Currently data collection for the fourth wave is being conducted, which will be completed by the end of 2010. For a more detailed description of the TRAILS cohort see Huisman et al. (2008).

At the third assessment wave (T3) a focus sample was selected from the total TRAILS sample $(n=1816)$ and invited to participate in a series of laboratory tasks in order 
to study a diversity of research questions within the TRAILS study. Of the 744 adolescents that were invited $715(96.1 \%)$ agreed to participate. This sample consisted of $473(66.2 \%)$ adolescents with an increased risk to develop mental health problems in order to increase the power to detect mental health-related differences in response patterns. Increased risk was defined based on baseline temperament (high scores on frustration and fearfulness, low scores on effortful control), parental psychopathology (depression, anxiety, addiction, psychoses, or antisocial behavior), and environmental risk (living in a single-parent family). The other $33.8 \%(n=242)$ were randomly selected from the total TRAILS sample. Please note that, although increased risk adolescents were oversampled, the sample included the total range of mental health problems present in a community population of adolescents, only in a different distribution. The experimental protocol was approved by the Dutch Central Committee on Research Involving Human Subjects (CCMO).

Within the focus sample, 649 (90.8\%) adolescents were of Caucasian descent, of whom 592 (91.2\%) were successfully genotyped. We excluded adolescents who used analgesic (pain-relieving) drugs on the day of the experiment or the day before and/or SSRIs and/or corticosteroids ( $n=24$ ), because these medications can influence responses to stress (Holsboer and Barden 1996). Three girls were discarded because of missing information on OC-use. Eight adolescents were discarded because of detection failures in more than two saliva samples and/or irregularities in two or more interbeat-intervals (IBI) recording blocks. Hence, 553 adolescents (mean age 16.07 years, $\mathrm{SD}=0.90$, FC-girls $n=183$; OC-girls $n=93$; boys $n=277$ ) were included in the analyses.

\section{Procedures}

During the experimental session, participants' psychophysiological responses (cardiovascular, cortisol, subjective arousal) to a variety of challenging conditions were recorded (see Bouma et al. 2009 for details). In brief, the sessions took place on weekdays, in soundproof rooms with blinded windows at selected locations in the participants' residence town; lasted about $3 \mathrm{~h}$; and started between 0800 and $0930 \mathrm{~h}$ or between 1230 and $0230 \mathrm{~h} \mathrm{(57 \% ).} \mathrm{Adoles-}$ cents were randomly assigned to morning and afternoon sessions. The ratio of boys, FC-girls and OC-girls was not different between the morning and the afternoon sessions $\left(\chi^{2}(557,2)=0.35, p=0.84\right.$. Participants were asked to refrain from smoking and from using coffee, milk, chocolate, and other sugar-containing foods in the $2 \mathrm{~h}$ before the session. Data of morning and afternoon sessions were pooled.
The Groningen Social Stress Test (GSST)

The GSST is a standardized protocol, inspired by the Trier Social Stress Task (TSST; Kirschbaum et al. 1993), to induce moderate performance-related acute social stress. In short, participants were instructed to prepare a 6-min speech about themselves and their lives and perform difficult mental arithmetic in front of a camera. The GSST encompasses the three most important triggers of HPA axis: uncontrollability, threat of failure, and fear of negative social evaluation (Dickerson and Kemeny 2002). Participants were debriefed directly after the GSST. For a more detailed description of the GSST, please see Bouma et al. (2009).

\section{Genotyping}

DNA was extracted from blood samples or (in a few cases) buccal swabs (Cytobrush ${ }^{\circledR}$ ) using a manual salting out procedure as described by Miller et al. (1988). SNPs were selected on the basis of known or expected functionality and/or previous reported associations with physiological responses to stress. GR N363S (rs6195) was included in the initial selection but could not be genotyped because of incompatibility with other SNPs on the Illumina platform. Genotyping was performed on the Golden Gate Illumina BeadStation 500 platform (Illumina Inc., San Diego, CA, USA), following the manufacturers protocol. We used an assay which was designed within the framework of various research questions of the TRAILS study. Genotyping data and clustering was performed in BeadStudio 3.0 (Illumina Inc., San Diego, CA, USA). Call rates were 95\% for rs6198 (GR 9beta) and rs5522 (MR I180V), and 100\% for rs2070951 (MR-2G/C) and rs41423247 (GR BclI). Call rate of GR ER22 (rs6189) was lower (81\%) than the threshold of $95 \%$ and was excluded from statistical analysis. Concordance between DNA replicates showed a genotyping accuracy of $100 \%$. Data cleaning was in line with procedures recommended by Nolte et al. (2010). Calculations of linkage disequilibrium between SNPs were performed in Excel using an Expectation-Maximization algorithm.

\section{Measures}

Cortisol was assessed from saliva by the Salivette sampling device (Sarstedt, Numbrecht, Germany). The cortisol response to social stress was measured based on four cortisol samples. Sample 1 was taken just before the start of the GSST and reflects HPA axis activity when participants filled out a rating scale while sitting quietly. Sample 2 was 
collected directly after the end of the GSST and reflects HPA axis responses during the start of the GSST. Sample 3 reflects HPA axis activity around the end of the GSST. Sample 4 was collected 40 min after the end of the GSST and is considered to reflect post-stress activity of the HPA axis. Samples were brought to the laboratory of the University Medical Center in Groningen where they were stored at $-20^{\circ} \mathrm{C}$ until analysis. The intra-assay coefficient of variation was $8.2 \%$ for concentrations of $1.5 \mathrm{nmol} / \mathrm{l}$, $4.1 \%$ for concentrations of $15 \mathrm{nmol} / 1$, and $5.4 \%$ for concentrations of $30 \mathrm{nmol} / \mathrm{l}$. The inter-assay coefficients of variation were, respectively, 12.6, 5.6, and $6.0 \%$. The detection border was $0.9 \mathrm{nmol} / \mathrm{l}$. Missing cortisol samples (C1, $n=20, \mathrm{C} 2, n=24, \mathrm{C} 3, n=27, \mathrm{C} 4, n=24)$ were due to detection failures in the lab $(52 \%)$ or insufficient saliva in the tubes (48\%). Missing values were imputed on the basis of group mean and standard deviation, where group is either 'Boys', 'FC-girls', or 'OC-girls', and the (standardized) mean of participant's non-missing cortisol samples.

Heart rate $(H R)$ was recorded during and after the GSST in four blocks for several seconds: speech preparation (H1) (240 s), speech (H2) (360 s), mental arithmetic (H3) (360 s), and post test (H4) (300 s). A three-lead electrocardiogram was registered using 3M/RedDot- $\mathrm{Ag} / \mathrm{AgCl}$ electrodes (type 2255, 3M Health Care, D-41453 Neuss, Germany), while the participant was sitting and breathing spontaneously. With a BIOPAC Amplifier-System (MP100), the signals were amplified and filtered before digitization at 250 samples/s. Dedicated software (PreCARSPAN), previously used in, e.g., Dietrich et al. (2006) was used to check signal stationarity, to correct for artifacts, to detect R-peaks, and to calculate the IBI between two heart beats. IBI is inversely related to heart rate by the equation $\mathrm{HR}=60000 / \mathrm{IBI}$. HR was defined as the number of beats per minute (bpm). Blocks were considered invalid if they contained artifacts with duration of more than $5 \mathrm{~s}$, if the total artifact duration was more than $10 \%$ of the registration, or if the block length was less than $100 \mathrm{~s}$. Missing heart rate recordings $(\mathrm{H} 1, n=6, \mathrm{H} 2, n=3, \mathrm{H} 3, n=3$, $\mathrm{H} 4, n=6)$ were due to recording failure (42\%) or signalanalysis failure $(58 \%)$. Missing values were imputed in a similar way as described above for cortisol levels.

Cortisol and heart rate response variables were computed to analyze if the GSST induced significant increases in cortisol and heart rate. We determined the peak response (indicated by either $\mathrm{C} 2$ or $\mathrm{C} 3$ for cortisol and $\mathrm{H} 2$ or $\mathrm{H} 3$ for heart rate) and subtracted the pretest measure $(\mathrm{C} 1$ or $\mathrm{H} 1)$ from this peak. A difference larger than zero was considered a meaningful increase.

Use of $O C$ was assessed at the day of the experiment, while type and name of the pill were asked as part of a questionnaire that was assessed previously, at school. In total, OCs were used by 93 girls, of whom 66 (70.2\%) used a monophasic OC and four girls a tri-phasic Pill (both ethinylestradiol and progestagen based). Ten girls used the 'Diane' Pill, which contains only progestagen (cyproteronacetaat) and is mainly prescribed for the beneficial effects on acne vulgaris. Thirteen girls did not know what type of OC they used.

Depressed mood was assessed at the start of the experimental session, by means of the Dutch version of the short Profile of Mood Scale (POMS; Wald and Mellenbergh 1990). The Depressed Mood scale includes eight items describing current mood (down, helpless, sad, lonely, unhappy, unworthy, melancholic, desperate), which could be rated on a five-point scale $(1=$ not at all, $2=$ a little, $3=$ partly, $4=$ kind of, $5=$ very much). Cronbach's alpha was 0.87 .

\section{Statistical analysis}

Analyses were performed in SPSS (Version 14.0). Allele frequencies were calculated and analyzed for deviations from Hardy-Weinberg equilibrium (HWE) using $\chi^{2}$-tests with 1 degree of freedom. Means and standard deviations of all variables were calculated and gender differences were analyzed by Analysis of Variance (continuous variables) or $\chi^{2}$-tests (categorical variables). Cortisol and heart rate data were log-transformed (natural logarithm) to approach a normal distribution before analysis. Tables and figures show non-transformed data. Genotypes were examined concordant with earlier studies; GR 23EK: AG versus GG; GR $B c l$ I: $C C$ versus $C G$ versus GG, GR 9beta and MR I180V: AA versus AG/GG (Wüst et al. 2004; Kumsta et al. 2007; Ising et al. 2008). The novel MR-2G/C polymorphism was examined by the general genotype approach (GG versus GC versus $\mathrm{CC}$ ) assuming no specific inheritance model.

Genotype associations with cortisol and heart rate responses were examined by repeated-measures General Linear Modeling (GLM), with cortisol (C1, C2, C3, C4) or heart rate $(\mathrm{H} 1, \mathrm{H} 2, \mathrm{H} 3, \mathrm{H} 4)$ responses to the GSST as dependent variables, and genotype as between-subjects factor. When sphericity could not be assumed effects were corrected using the Greenhouse-Geisser procedure. Analyses were performed for each SNP separately. Interactions between genotype and cortisol or heart rate indicate genotypic differences in changes in cortisol or heart rate during the task. In case of significant interactions, linear and quadratic trends were examined to explore the nature of the differences. A linear trend signifies an overall rise or fall in cortisol levels or heart rate during the test, while a quadratic trend indicates higher levels during the test than before and after. Analyses were performed separately for 
boys, FC-girls and OC-girls. Depressed mood was included as a covariate since it may be associated with both the genotypes under study and cortisol and heart rate responses to stress (Hughes and Stoney 2000; Burke et al. 2005; van Rossum et al. 2006; van West et al. 2006; Kuningas et al. 2006; Carroll et al. 2007). Analyses were controlled for time of day (morning or afternoon). Menstrual cycle phase was not considered in the analyses. This was reasoned from the absence of an effect of cycle phase on the cortisol response in a previous study of this adolescent sample (Bouma et al. 2009).

Since 30 associations were tested (five SNP genotypes with two phenotypes in three 3 groups), a correction for multiple testing had to be applied. We used the false discovery rate (FDR) procedure proposed by Benjamini and Hochberg (1995). As the response phenotypes (in this case cortisol and heart rate) were correlated ( $r=0.17$, we applied the FDR correction for each phenotype separately, resulting in an alpha threshold of 0.003 .

\section{Results}

\section{Descriptive statistics}

All SNPs were in HWE. Frequencies of alleles and genotypes can be found in Table 1. The two SNPs in the GR gene and in the MR gene were not correlated with each other ( $r^{2}<0.2$ for both pairs). The linkage disequilibrium measure $D^{\prime}$ was $>0.98$ for both pairs, indicating strongly reduced recombination between the SNPs within a gene, but independent evolutionary histories of the mutations. Genotype frequencies did not differ between boys, FC-girls, and OC-girls (shown in Table 1).

Table 2 shows descriptive statistics, separately for the three groups (Boys, FC-girls, and OC-girls). The group difference for age was due to the fact that OC-girls were somewhat older than FC-girls $(p=0.001)$. OC using girls had higher cortisol levels on sample 1 compared to FC-girls $(p<0.001)$ and boys $(p=0.001)$. Boys had higher cortisol levels on sample $2(p<0.01)$ compared to
FC-girls. Group differences in heart rate were caused during preparation and speech by boys having lower heart rates than girls $(p<0.001)$, regardless of OC use. The group differences during arithmetic was caused by boys having lower heart rate than FC-girls $(p<0.001)$ and the difference during post stress was due to boys having lower heart rates than OC-girls $(p=0.01)$. Girls, irrespective of OC-use, reported more depressed mood than boys $(p<0.02)$.

Cortisol and heart rate responses were associated in FC-girls $(r=0.27 ; p<0.01)$ and in boys $(r=0.15$; $p<0.001)$ but not in OC-girls. A rise in cortisol levels between the pretest $(\mathrm{C} 1)$ and levels during the stress tests (C2 and C3) was observed in most FC-girls (72\%) and boys $(78 \%)$. As expected from previous findings in this sample (Bouma et al. 2009), a rise in cortisol levels was largely absent in OC-girls; only $40 \%$ showed a small increase. Heart rate increased from pretest $(\mathrm{H} 1)$ to speech $(\mathrm{H} 2)$ or mental arithmetic (H3) in most participants; FC-girls (81\%), boys $(80 \%)$, and OC-girls $(72 \%)$.

No associations between SNP genotype and physiological stress responses

The results of the tests for interaction effects of genotype with cortisol and heart rate can be found in Tables 3 (cortisol) and 4 (heart rate), for boys, FC-girls and OC-girls separately indicated. When applying our adjusted alpha threshold of 0.003 , to account for the consequences of multiple testing, no significant associations are present.

\section{Discussion}

Our aim was to replicate previous reports of associations between SNPs in the GR and MR genes and HPA axis and cardiac autonomic responses to social stress in a large sample of adolescents. We examined associations separately for boys, FC-girls and OC-girls. None of the previously reported associations in adult samples could be replicated in this large adolescent sample. GR9beta was not associated with cortisol in boys and OC-girls in our

Table 1 Allele frequencies and differences between boys, FC girls and OC users

\begin{tabular}{|c|c|c|c|c|c|c|c|c|}
\hline \multirow{2}{*}{$\frac{\text { Polymorphism }}{\text { GR22EK }}$} & \multirow{2}{*}{$\begin{array}{l}\text { rs number } \\
\text { rs6190 }\end{array}$} & \multirow{2}{*}{$\frac{\mathrm{SNP}}{\mathrm{G} \rightarrow \mathrm{A}}$} & \multirow{2}{*}{$\frac{\text { MAF }}{0.03}$} & \multicolumn{3}{|c|}{$n$ in genotype group } & \multicolumn{2}{|c|}{ Group difference } \\
\hline & & & & $\mathrm{GG}=524$ & $\mathrm{AG}=29$ & - & $\chi^{2}=0.04$ & $p=0.98$ \\
\hline GRBclI & rs41423247 & $\mathrm{C} \rightarrow \mathrm{G}$ & 0.38 & $\mathrm{CC}=214$ & $\mathrm{CG}=254$ & $\mathrm{GG}=85$ & $\chi^{2}=7.45$ & $p=0.11$ \\
\hline GR9beta & rs6198 & $\mathrm{A} \rightarrow \mathrm{G}$ & 0.15 & $\mathrm{AA}=401$ & $A G=136$ & $\mathrm{GG}=16$ & $\chi^{2}=8.70$ & $p=0.07$ \\
\hline MRI180V & rs5522 & $\mathrm{A} \rightarrow \mathrm{G}$ & 0.14 & $\mathrm{AA}=409$ & $\mathrm{AG}=139$ & $\mathrm{GG}=5$ & $\chi^{2}=0.69$ & $p=0.95$ \\
\hline MR-2G/C & rs2070951 & $\mathrm{G} \rightarrow \mathrm{C}$ & 0.49 & $\mathrm{GG}=137$ & $\mathrm{CG}=289$ & $\mathrm{CC}=127$ & $\chi^{2}=4.50$ & $p=0.34$ \\
\hline
\end{tabular}

Details on group differences are described in the "Result" section

$M A F$ minor allele frequency 
Table 2 Descriptive statistics

\begin{tabular}{|c|c|c|c|c|c|c|c|c|}
\hline \multirow[t]{2}{*}{ Variable } & \multicolumn{2}{|c|}{ Boys } & \multicolumn{2}{|c|}{ Girls FC } & \multicolumn{2}{|c|}{ Girls OC } & \multicolumn{2}{|l|}{ Group difference } \\
\hline & $n$ & Mean (SD) & $n$ & Mean (SD) & $n$ & Mean (SD) & Test statistic & $p$-value \\
\hline Age (years) & 277 & $16.10(0.58)$ & 183 & $15.99(0.54)$ & 93 & $16.34(0.64)$ & $F(2,556)=7.45$ & 0.001 \\
\hline Depressed mood & 274 & $1.21(0.38)$ & 183 & $1.36(0.53)$ & 93 & $1.36(0.45)$ & $F(2,553)=7.84$ & $<0.001$ \\
\hline $\mathrm{C} 1(\mathrm{nmol} / \mathrm{l})$ & 277 & $3.82(12.90)$ & 183 & $3.32(3.90)$ & 93 & $5.65(6.58)$ & $F(2,552)=10.45$ & $<0.001$ \\
\hline $\mathrm{C} 2(\mathrm{nmol} / \mathrm{l})$ & 277 & $5.49(4.40)$ & 183 & $4.43(4.90)$ & 93 & $4.55(3.87)$ & $F(2,553)=3.62$ & 0.03 \\
\hline C3 (nmol/l) & 277 & $4.81(3.39)$ & 183 & $5.20(6.60)$ & 93 & $4.18(3.62)$ & $F(2,553)=1.43$ & 0.24 \\
\hline C4 (nmol/l) & 277 & $3.76(1.69)$ & 183 & $4.34(5.22)$ & 93 & $4.09(4.06)$ & $F(2,552)=1.46$ & 0.23 \\
\hline H1 (bpm) & 266 & $74.83(10.30)$ & 178 & $81.02(10.89)$ & 89 & 80.47 (11.69) & $F(2,533)=22.76$ & $<0.001$ \\
\hline H2 (bpm) & 266 & $78.30(11.60)$ & 178 & $87.09(14.08)$ & 89 & $84.49(13.41)$ & $F(2,532)=26.83$ & $<0.001$ \\
\hline H3 (bpm) & 266 & 76.17 (10.94) & 178 & $80.94(12.42)$ & 89 & $79.31(11.49)$ & $F(2,532)=9.55$ & $<0.001$ \\
\hline H4 (bpm) & 266 & $67.94(9.84)$ & 178 & $70.00(9.59)$ & 89 & $71.62(10.96)$ & $F(2,532)=9.37$ & $<0.01$ \\
\hline
\end{tabular}

Details on group differences can be found in the "Result" section

$F C$ free-cycling, $O C$ oral contraceptives. Responses during the GSST: $C 1$ pre-stress cortisol, $C 2$ cortisol during social stress, $C 3$ post-stress cortisol, $\mathrm{C} 4$ post-stress cortisol, $H 1$ heart rate during preparation, $H 2$ heart rate during speech, $H 3$ heart rate during mental arithmetic, $H 4$ poststress heart rate, $S D$ standard deviation

Table 3 Effects of SNP genotype on the cortisol response to the GSST

\begin{tabular}{lll}
\hline & Test statistic & $p$-value \\
\hline GR23EK & & \\
Boys & $F(3,257)=0.38$ & 0.69 \\
FC-girls & $F(3,162)=0.90$ & 0.41 \\
OC-girls & $F(3,76)=0.69$ & 0.49 \\
GRBclI & & \\
Boys & $F(6,256)=0.74$ & 0.57 \\
FC-girls & $F(6,161)=1.45$ & 0.22 \\
OC-girls & $F(6,75)=0.51$ & 0.72 \\
GR9beta & & \\
Boys & $F(3,257)=0.39$ & 0.68 \\
FC-girls & $F(3,162)=3.25$ & 0.04 \\
OC-girls & $F(3,76)=2.02$ & 0.14 \\
MRI180V & & \\
Boys & $F(3,257)=0.67$ & 0.94 \\
FC-girls & $F(3,162)=1.42$ & 0.24 \\
OC-girls & $F(3,76)=0.34$ & 0.70 \\
MR-2G/C & & \\
Boys & $F(6,256)=0.89$ & 0.47 \\
FC-girls & $F(6,161)=2.58$ & 0.04 \\
OC-girls & $F(6,75)=2.83$ & 0.03 \\
\hline All analyse & & \\
\hline
\end{tabular}

All analyses were corrected for depressed mood and time of day. Uncorrected degrees of freedom are reported

GSST Groningen Social Stress Task, FC free-cycling, $O C$ oral contraceptives

adolescent sample as reported previously by Kumsta et al. (2007). Findings regarding GRBclI and cortisol in men and OC-girls (Wüst et al. 2004; Kumsta et al. 2007; Ising et al.
Table 4 Effects of SNP genotype on the heart rate response to the GSST

\begin{tabular}{lll}
\hline & Test statistic & $p$-value \\
\hline GR23EK & & \\
Boys & $F(3,246)=1.25$ & 0.29 \\
FC-girls & $F(3,157)=0.35$ & 0.74 \\
OC-girls & $F(3,72)=0.97$ & 0.38 \\
GRBclI & & \\
Boys & $F(6,245)=0.65$ & 0.70 \\
FC-girls & $F(6,156)=0.29$ & 0.91 \\
OC-girls & $F(6,71)=1.28$ & 0.28 \\
GR9beta & & \\
Boys & $F(3,245)=0.48$ & 0.67 \\
FC-girls & $F(3,156)=0.06$ & 0.96 \\
OC-girls & $F(3,71)=0.02$ & 0.86 \\
MRI180V & & \\
Boys & $F(3,246)=0.83$ & 0.47 \\
FC-girls & $F(3,157)=0.49$ & 0.65 \\
OC-girls & $F(3,72)=2.25$ & 0.11 \\
MR-2G/C & & \\
Boys & $F(6,245)=0.35$ & 0.89 \\
FC-girls & $F(6,156)=1.27$ & 0.27 \\
OC-girls & $F(3,72)=5.00$ & 0.007 \\
\hline All analyses & & \\
\hline
\end{tabular}

All analyses were corrected for depressed mood and time of day. Uncorrected degrees of freedom are reported

GSST Groningen Social Stress Task, FC free-cycling, $O C$ oral contraceptives

2008) were also not replicated. The association between MR I180V and heart rate response patterns previously reported in adults (DeRijk et al. 2006) was also not present 
in adolescents. None of the GR variants was associated with heart rate which partly supports the suggestion by DeRijk and de Kloet (2008) that cardiac autonomic responses do not seem to be affected by GR variants. The MR-2G/C SNP was also not associated with cortisol and heart rate in any of the three groups.

Inconsistencies in results between the present and previous studies could be due to differences in sample characteristics and dissimilarity in the application of correction for multiple testing. First, whereas previous samples consisted of (young) adults, our sample concerned adolescents. The adolescent brain seems especially sensitive to psychosocial stress (Perlman et al. 2007). Genetically based differences in corticoid receptors could affect the activation and feedback of the HPA axis during stressful situations differently in adolescence compared to adulthood. Second, long-term use of synthetic sex hormones might have other effects on physiological stress responses than the relatively short use (max. 18 months) in our adolescent sample. Longitudinal research, such as the TRAILS study, is needed to elucidate the long-term effects of OC use on HPA axis functioning (Ott et al. 2008). Third, the question might be raised if oversampling of increased-risk adolescents affected the distribution of genotypes in our study. This is not the case; allele frequencies of the SNPs under study did not differ between the total number of genotyped participants in the TRAILS focus sample $(n=592)$ and the TRAILS population sample $(n=1246)$ (data available on request). In addition to this, the cortisol response and heart rate response was not different according to risk status (increased or low) (results of these analyses also available on request). Fourth, the cortisol levels reflecting HPA axis activation during speech and arithmetic were lower than those reported in adults. This might be due to age-related differences as previously discussed, but may also be explained by differences in the stress protocols used. The main difference between the TSST and the GSST concerns the amount of social evaluation: a panel of three judges (TSST) versus one experimenter and a video camera (GSST). But even if this difference led to a lower stress appraisal compared to the TSST, we do not consider this a limitation of our study. Individual differences in stress responses to mild stressors may be just as important to investigate as the responses to more extreme stressors. Our GSST protocol induced significant cortisol responses, as well as meaningful between-group differences. Fifth, another reason for discrepancies is the fact that the results of the present study were corrected for multiple testing while previous results were not (except for those reported by Ising et al. 2008). Initially, we found four significant associations, three in the GR and one in the MR gene, but after correcting the alpha threshold for multiple testing, these results could not be considered as statistically valid.
It should be noted that the associations we found without correction for multiple testing were not in the same SNPs as reported before.

Our findings should be viewed in the light of the following limitations. First, the social stress test was the last task of the experimental session and we do not know to what extent this may have influenced heart rate and cortisol responses. However, systematic bias in our associations is not likely, because the social stress test was by far the most stressful element of the session (data available on request). Second, we examined physiological responses in morning and afternoon sessions, which could have made direct comparisons with the previous studies having afternoon sessions only, difficult. However, time of day does not influence cortisol response pattern, not in adults (Kudielka et al. 2004) and not in adolescent boys and FC girls (Bouma et al. 2009). Therefore, we see no reason to believe that this methodological difference between studies could have influenced the non-replication of previous results. Third, the social stress task involved speaking aloud, which may have obscured associations with genotype since Sloan et al. (1991) reported that speaking during a stressful task decreases heart rate responses. Fourth, correcting for depressed mood in the analyses might have mask effects as GR SNPs are associated with depression and depressed mood (van Rossum et al. 2006; van West et al. 2006; Kuningas et al. 2006). However, re-analyzing the data without including depressed mood as covariate did not change the results.

Since our sample size is much larger $(>500)$ compared to those of previous studies (Wüst et al. 2004; DeRijk et al. 2006; Kumsta et al. 2007; Ising et al. 2008), and we had sufficient power $(>80 \%)$ to detect a medium size effect (based on calculations recommended by Nolte et al. 2010), the question must be raised if some of the previously reported associations should be considered false positive findings.

\section{Funding}

TRAILS has been financially supported by various grants from the Netherlands Organization for Scientific Research NWO (Medical Research Council program grant GB-MW 940-38-011; ZonMW Brainpower grant 100-001-004; ZonMw Risk Behavior and Dependence grants 60-6060098-018 and 60-60600-97-118; ZonMw Culture and Health grant 261-98-710; Social Sciences Council medium-sized investment grants GB-MaGW 480-01-006 and GB-MaGW 480-07-001; Social Sciences Council project grants GB-MaGW 457-03-018, GB-MaGW 452-04-314, and GB-MaGW 452-06-004; NWO large-sized investment grant 175.010.2003.005); the Sophia Foundation for Medical Research (projects 301 and 393), the Dutch Ministry of Justice (WODC), the European Science Foundation 
(EuroSTRESS project FP-006), and the participating universities. These sponsors had no involvement in study design, collection, analysis and interpretation of the data, nor in writing or decisions regarding the submission of the paper.

Acknowledgments We are grateful to all adolescents and their parents who participated in this research and to everyone who worked on this project and made it possible. Special thanks to Roel de Rijk and Nienke van Leeuwen for their SNP selection suggestions and expertise concerning the functionality of the mineralocorticoid receptor. Thanks to Gerrit van der Steege for his advise on the genotyping procedure, and to Eryn Liem for her help in the DNA preparation phase.

Open Access This article is distributed under the terms of the Creative Commons Attribution Noncommercial License which permits any noncommercial use, distribution, and reproduction in any medium, provided the original author(s) and source are credited.

\section{References}

Altemus M, Redwine L, Leong YM, Yoshikawa T, Yehuda R, Detera-Wadleigh S, Murphy DL (1997) Reduced sensitivity to glucocorticoid feedback and reduced glucocorticoid receptor mRNA expression in the luteal phase of the menstrual cycle. Neuropsychopharmacology 17:100-109

Benjamini Y, Hochberg Y (1995) Controlling for the False Discovery Rate: a practical and powerful approach to multiple testing. J R Stat Soc Series B Stat Methodol 157:289-300

Bouma EMC, Riese H, Ormel J, Verhulst FC, Oldehinkel AJ (2009) Adolescents' cortisol responses to awakening and social stress; effects of gender, menstrual phase and oral contraceptives. The TRAILS study. Psychoneuroendocrinology 34:884-893

Brody S (2002) Age at first intercourse is inversely related to female cortisol stress reactivity. Psychoneuroendocrinology 27:933-943

Burke HM, Davis MC, Otte C, Mohr DC (2005) Depression and cortisol responses to psychological stress: a meta-analysis. Psychoneuroendocrinology 30:846-856

Carroll D, Phillips AC, Hunt K, Der G (2007) Symptoms of depression and cardiovascular reactions to acute psychological stress: evidence from a population study. Biol Psychol 75:68-74

Chrousos GP, Torpy DJ, Gold PW (1998) Interactions between the hypothalamic-pituitary-adrenal axis and the female reproductive system, clinical implications. Ann Intern Med 129:229-240

de Kloet ER, Fitzsimons CP, Datson NA, Meijer OC, Vreudenhil E (2009) Glucocorticoid signaling and stress-related limbic susceptibility pathway: about receptors, transcription machinery and microRNA. Brain Res 1293:129-141

de Winter A, Oldehinkel AJ, Veenstra R, Brunnekreef JA, Verhulst FC, Ormel J (2005) Evaluation of non-response bias in mental health determinants and outcomes in a large sample of preadolescents. Eur J Epidemiol 20:173-181

DeRijk RH (2009) Single nucleotide polymorphisms related to HPA axis activity. Neuroimunomodulation 16:340-352

DeRijk RH, de Kloet ER (2008) Corticosteroid receptor polymorphisms: determinants of vulnerability and resilience. Eur $\mathrm{J}$ Pharmacol 583:303-311

DeRijk RH, Wüst S, Meijer OC, Zennaro MC, Federenko IS, Hellhammer DH, Giacchetti G, Vreugdenhil E, Zitman FG, de Kloet ER (2006) A common polymorphism in the mineralocorticoid receptor modulates stress responsiveness. J Clin Endocrinol Metab 91:5083-5089
Dickerson SS, Kemeny ME (2002) Acute stressors and cortisol responses: a theoretical integration and synthesis of laboratory research. Psychol Bull 130:355-391

Dietrich A, Riese H, van Roon AM, van Engelen K, Ormel J, Neeleman J, Rosmalen JGM (2006) Spontaneous baroreflex sensitivity in (pre)adolescents. J Hypertens 24:345-352

Holsboer F, Barden N (1996) Antidepressants and hypothalamicpituitary-adrenocortical regulation. Endocr Rev 17:187-205

Hughes JW, Stoney CM (2000) Depressed mood is related to highfrequency heart rate variability during stressors. Psychosom Med 62:796-803

Huisman M, Oldehinkel AJ, de Winter A, Minderaa RB, de Bildt A, Huizink AC, Verhulst FC, Ormel J (2008) The Dutch 'TRacking Adolescents' Individual Lives' Survey' TRAILS. Int J Epidemiol 37:1227-1235

Ising M, Depping A, Siebertz A, Lucea S, Unschuld PG, Kloiber S, Horstmann S, Uhr M, Müller-Kyhsok B, Holsboer F (2008) Polymorphisms in the FKBP5 region modulate recovery from psychosocial stress in health controls. Eur $\mathrm{J}$ Neurosci 28:389-398

Kendler KS, Gatz M, Gardner CO, Pedersen N (2006) A Swedisch twin study of lifetime major depression. Am J Psychiatry 163:109-114

Kirschbaum C, Pirke KM, Hellhammer DH (1993) The Trier Social Stress Test-a tool for investigating psychobiological stress responses in a laboratory setting. Neuropsychobiology 28:76-81

Kirschbaum C, Kudielka BM, Gaab J, Schommer NC, Hellhammer DH (1999) Impact of gender, menstrual cycle phase, and oral contraceptives on the activity of the hypothalamus-pituitaryadrenal axis. Psychosom Med 61:154-162

Kudielka BM, Schommer NC, Hellhammer DH, Kirschbaum C (2004) Acute HPA axis responses, heart rate, and mood changes to psychosocial stress (TSST) in humans at different times of day. Psychoneuroendocrinology 28:983-992

Kumsta R, Entringer S, Koper JW, van Rossum EF, Hellhammer DH, Wüst S (2007) Sex specific associations between common glucocorticoid receptor gene variants and hypothalamus-pituitary-adrenal axis responses to psychosocial stress. Biol Psychiatry 62:863-869

Kuningas M, Mooijaart SP, Slagboom PE, Westendorp RG, van Heemst D (2006) Genetic variants in the glucorticoid receptor gene (NR3C1) and cardiovascular disease risk. The Leiden 85plus Study. Biogerontology 7:231-238

Levine JE (2002) Editorial, stressing the importance of sex. Endocrinology 143:4502-4504

Miller SA, Dykes DD, Polesky HF (1988) A simple salting out procedure for extracting DNA from human nucleated cells. Nucl Acids Res 16:1215

Nolte IM, McCaffery JM, Snieder H (2010) Candidate gene and genome-wide association studies in behavioral medicine. In: Steptoe A (ed) Handbook of behavioral medicine: methods and applications. Springer, New York

Ott MA, Shew ML, Ofner S, Tu W, Fortenberry JD (2008) The influence of hormonal contraception on mood and sexual interest among adolescents. Arch Sex Behav 37:605-613

Perlman WR, Webster MJ, Herman MM, Kleinman JE, Weickert CS (2007) Age-related differences in glucocorticoid receptor mRNA levels in the human brain. Neurobiol Aging 28:447-458

Rohleder N, Wolf JM, Piel M, Kirschbaum C (2003) Impact of oral contraceptive use on glucocorticoid sensitivity of pro-inflammatory cytokine production after psycho-social stress. Psychoneuroendocrinology 28:261-273

Russcher H, van Rossum EF, de Jong FH, Brinkman AO, Lamberts SW, Koper JW (2005) Increased expression of the glucocorticoid receptor-A translational isoform as a result of the ER22/ 23EK polymorphism. Mol Endocrinol 19:1687-1696 
Sainani KL (2009) The problem of multiple testing. Am J Phys Med Rehabil 1:1098-1103

Silberg JL, Pickles A, Rutter M, Eaves L (1999) The influence of genetic factors and life stress on depression among adolescent girls. Arch Gen Psychiatry 56:225-232

Sloan RP, Korten JB, Myers MM (1991) Components of heart rate reactivity during mental arithmetic with and without speaking. Physiol Behav 50:1039-1045

Turner BB (1997) Influence of gonadal steroids on brain corticosteroid receptors: a minireview. Neurochem Res 22:1375-1385

van Leeuwen N, Wüst S, Meijer OC, de Kloet ER, Zitman FG, DeRijk RH (2007) An in vitro functional SNP in the mineralocorticoid receptor (MR) is associated with the cortisol awakening rise (CAR) and stress response. World Congress on Psychiatric Genetics Abstract

van Leeuwen N, Kumsta R, Entringer S, de Kloet ER, Zitman FG, Derijk RH, Wüst $S$ (2010) Functional mineralocorticoid receptor (MR) gene variation influences the cortisol awakening response after dexamethasone. Psychoneuroendocrinology 35:339-349

van Rossum EF, Feelders RA, van den Beld AW, Uitterlinden AG, Janssen JA, Ester W, Brinkmann AO, Grobbee DE, de Jong FH, Pols HA, Koper JW, Lamberts SW (2004) Association of the ER22/23EK polymorphism in the glucocorticoid receptor gene with survival and C-reactive protein levels in elderly men. Am J Med 117:158-162 van Rossum EF, Binder EB, Majer M, Koper JW, Ising M, Modell S, Salyakina D, Lamberts S, Holsboer F (2006) Polymorphisms of the glucocorticoid receptor gene and major depression. Biol Psychiatry 59:681-688

van West D, Van Den Eede F, Del-Favero J, Souery D, Norrback KF, Van Duijn C, Sluijs S, Adolfsson R, Mendlewicz J, Deboutte D, Van Broeckhoven C, Claes S (2006) Glucocorticoid receptor gene-based SNP analysis in patients with recurrent depression. Neuropsychopharmacology 31:620-627

Wald FDM, Mellenbergh GJ (1990) De verkorte versie van de Nederlandse vertaling van de Profile of Mood States (POMS), the shortened version of the Dutch translation of the Profile of Mood States (POMS). Ned Tijdschr Psychol 45:86-90

Wiegratz I, Kutschera E, Lee JH, Moore C, Mellinger U, Winkler UH, Kuhl H (2003) Effect of four different oral contraceptives on various sex hormones and serum-binding globulins. Contraception 67:25-32

Wolf OT, Schommer NC, Hellhammer DH, McEwen BS, Kirschbaum C (2001) The relationship between stress induced cortisol levels and memory differs between men and women. Psychoneuroendocrinology 26:711-720

Wüst S, van Rossum EF, Federenko IS, Koper JW, Kumsta R, Hellhammer DH (2004) Common polymorphisms in the glucocorticoid receptor gene are associated with adrenocortical responses to psychosocial stress. J Clin Endocrinol Metab 89:565-573 